\title{
Experiences of Intensive Care Nurses in Caregiving for Coronavirus (COVID-19) Patients: A Phenomenological Approach
}

\section{Koronavirüs (COVID-19) Hastalarına Bakım Veren Yoğun Bakım Hemşirelerinin Deneyimleri: Fenomenolojik Bir Yaklaşım}

\author{
Sibel Şentürk ${ }^{1}$ (iD) Alev Yıldırım Keskin ${ }^{2}$ iD \\ ' Department of Nursing, Bucak Health School, Burdur Mehmet Akif Ersoy University, Bucak-Burdur, TURKEY \\ ${ }^{2}$ Department of Nursing, Akșehir Kadir Yallagöz Health School, Selçuk University, Akşehir-Konya, TURKEY. \\ Geliş tarihi/ Date of receipt: 05/04/2021 Kabul tarihi/ Date of acceptance: 14/06/2021 \\ (c) Ordu University Faculty of Health Sciences, Department of Nursing, Turkey, Published online: 08/09/2021
}

\begin{abstract}
Objective: This study was conducted to specify the caregiving experiences of intensive care nurses who provided care to coronavirus (COVID-19) patients.

Methods: The experiences of intensive care nurses were quoted with a phenomenological approach. The data were collected from 25 intensive care nurses over Skype using a semi-structured interview form between July 21 and August 31, 2020. In data analysis, Colaizzi's phenomenological method was used.

Results: As a result of the coding process, 3 themes were determined as (1) Difficulties: It was revealed that the intensive care nurses experienced physical, psychological and family relations/family environment difficulties; (2) Achievements: The nurses expressed that they had achievements related to professionalization/professional satisfaction, teamwork and the concepts of life and death in the caregiving process; (3) Coping strategies: The participants stated that they used positive coping strategies such as orientation to religion, exercise and music and negative coping strategies such as smoking and alcohol consumption during their period of caregiving for COVID-19 patients.
\end{abstract}

Conclusion: Struggling with a pandemic caused the intensive care nurses to be physically, psychologically and emotionally exhausted. Intensive care nurses should be given coping training on crisis management, and psychological support should be provided to them.

Keywords: Intensive care, nursing, COVID-19, caregiving, phenomenological approach.

\section{ÖZ}

Amaç: Bu çalışma, COVID-19 hastalarına bakım veren yoğun bakım hemşirelerinin bakım verme deneyimlerini belirlemek amacıyla yapılmıştır.

Yöntem: Yoğun bakım hemşirelerinin deneyimleri fenomenolojik yaklaşım ile aktarılmıştır. Veriler, yarı yapılandırılmış görüşme formu ile skype üzerinden 25 yoğun bakım hemşiresi ile 21 Temmuz-31 Ağustos 2020 tarihleri arasında toplanmıştır. Verilerin analizinde Colaizzi'nin fenomenolojik yöntemi kullanılmıştır.

Bulgular: Yapılan kodlamalar sonucunda 3 tema belirlenmiştir. (1) Zorluklar: Yoğun bakım hemşirelerinin fiziksel, psikolojik ve aile içi ilişkiler/aile ortamında zorluklar yaşadıkları belirlenmiştir. (2) Kazanımlar: Hemşireler bakım sürecinde profesyonelleşme/mesleki doyum, ekip çalışması, yaşam ve ölüm kavramları ile ilgili kazanımlar elde ettiklerini belirtmişlerdir. (3) Baş etme stratejileri: COVID19 hastalarına bakım verme sürecinde dine yönelim, egzersiz, müzik gibi olumlu baş etme stratejileri, sigara ve alkol tüketimi gibi olumsuz baş etme stratejilerini kullandıklarını belirtmişlerdir.

Sonuç: Salgın bir hastalıkla mücadele etmek yoğun bakım hemşirelerinin fiziksel, psikolojik ve duygusal olarak tükenmelerine neden olmuştur. Yoğun bakım hemşirelerine kriz yönetimine ilişkin baş etme eğitimleri verilmeli ve psikolojik destek sağlanmalıdır.

Anahtar Kelimeler: Yoğun bakım, hemşirelik, COVID-19, bakım verme, fenomenolojik yaklaşım. 


\section{Introduction}

The COVID-19 outbreak started in Wuhan, China in December 2019 and affected the whole world. It has been declared as an international public health emergency by the World Health Organization (Huang et al., 2020; Lu et al., 2020). As of 18.05.2021, more than 162.7 million cases of COVID-19 had been reported, and 3.3 million deaths had occurred (WHO, 2021). In Turkey, since the first case, the total number of cases has been reported as 5.1 million, whereas the total number of deaths was reported as 44,983 ( $\mathrm{MH}, 2021)$. In evaluations, it is stated that although $80 \%$ of these patients progress with a mild/moderate clinical status, the disease causes severe and critical illness that requires intensive care in $20 \%$ of cases (Akalın and Modanlıoğlu, 2021).

COVID-19 has been transmitted to a large number of people in need of medical treatment since its emergence, causing a large number of hospitalizations to occur in hospitals in a short time and an increase in the occupancy rate of intensive care units (Duygulu et al., 2020). Patients infected with COVID-19 have an increased risk of developing acute and chronic respiratory failure that requires intensive care support. Many of them need specific life support interventions such as extracorporeal membrane oxygenation, continuous renal replacement therapy and prone ventilation. Due to the complex intervention and care requirements of patients in intensive care units, the presence of qualified and expert intensive care nurses has gained strategic importance in this process (Chegini et al., 2021; Kiraner et al., 2021).

Intensive care nurses are the people in close contact with patients who are intubated, have complicated conditions and need to be provided with care, and they ensure implementation of infection prevention and control measures and compliance with these measures through their knowledge and experiences to limit infections. Among healthcare professionals, intensive care nurses are the leading professionals in the struggle against the COVID-19 pandemic, and their duties, roles and responsibilities have increased even more than those of other healthcare professionals (Buheji and Buhaid, 2020; Qiu et al., 2020).

In studies conducted with health professionals in various countries, mostly nurses, who provide care to COVID-19 patients, it has been expressed that the professionals sacrifice their comfort for the sake of professional responsibility and professionalism, and they experience physical and psychological problems such as being at high risk of infection and fear of infecting others, fear of death, excessive workload, pain, fatigue, disappointment, discrimination, social isolation, exhaustion, depression, anxiety, insomnia, psychological distress, panic disorder and obsession (Kang et al., 2020; Liu et al., 2020; Ramaci et al., 2020; Romero et al., 2020; Sethi et al., 2020; Sun et al., 2020). Despite all precautions, according to WHO data, 1 out of every 7 COVID-19 patients in the world consists of healthcare professionals (WHO, 2021). In Turkey, the number of healthcare workers infected with COVID-19 is over 120 thousand, and 1 out of every 10 COVID-19 patients is stated to be a healthcare worker (MH, 2021).

Considering these rates, countries should be ready for pandemics like COVID-19 that maybreak out in the future, and protective and supportive mental-social measures need to be taken for intensive care nurses, who work at the forefront, to protect their physical and psychological health (Buheji and Buhaid, 2020; Izci, 2020). The literature review has revealed, however, that qualitative studies conducted on the physical and psychological problems of nurses during the COVID-19 period in different countries are limited (Liu et al., 2020; Sun et al., 2020; Chegini et al., 2021). Further clarification of experiences of caring for COVID-19 patients in different societies and cultures may help nurses better define the situation and cope better with the process. Providing care for COVID-19 patients under harsh working conditions and sanctions is a special experience. Considering the uniqueness and unknown characteristics of this experience, it is important to determine the difficulties, gains and coping strategies of intensive care nurses in Turkey during their process of providing care for COVID-19 patients. It is believed that the results of this study will help make appropriate plans for possible future outbreaks.

The aim of this study is to determine the experiences of intensive care nurses who provide care to COVID-19 patients in Turkey.

\section{Methods}

Study Design: The research was planned as a phenomenological qualitative study.

Sample: The population of this study consisted of intensive care nurses who provided care to patients infected with COVID-19 in a district state hospital in Burdur. The purposive and snowball sampling methods were used in recruiting the sample. In the purposive sampling process, the 
characteristics of those to be included in the study were identified. The sample consisted of a total of 25 intensive care nurses who (a) were working in an intensive care unit for at least 1 year, (b) were working in intensive care units at the time of the study and providing care for patients infected with COVID-19, and (c) agreed to participate in the study. Snowball sampling was used in reaching the sample. In snowball sampling, a participant is recruited out of the intended population through interviews, this participant recruits the second one, the second participant recruits the third one and so on. In this manner, the sample size is increased. In our study, first of all, the nurse in charge of intensive care was interviewed because she had a command of all issues related to intensive care during the COVID-19 pandemic process. Later, on the days when the in-charge nurse came to work, she informed other nurses in the intensive care unit about the study. The nurses who wanted to participate in the study were interviewed by phone, and they were asked to inform their other friends during their shifts. This way, the sample was reached. For phenomenological qualitative research, no rules have been determined regarding sample size. However, it is known that when the answers of the participants in the sample of a study start to be similar to each other, the study reaches a saturation point, and the data collection process is stopped (Yıldırım and Şimşek, 2016). The interview process was terminated after 25 individual interviews.

\section{Data Collection}

The data were collected by conducting various in-depth individual interviews via a semi-structured questionnaire. The interviews were held between July 21 and August 31, 2020. Due to the COVID-19 pandemic process, the interviews were conducted on Skype by one of the researchers, who has a $\mathrm{PhD}$ degree in internal diseases nursing, on a jointly determined day and time on the days when the nurses were not working. The intensive care nurses who were included in the study were asked to download the Skype program to their computers or phones so that the interviews could be carried out. Before starting the interviews, the research protocol was explained to the participants. The intensive care nurses were asked to participate in the interview in a quiet room so that the interviews could be conducted properly. Each interview was completed in approximately 35-40 minutes. During the interviews, the statements of intensive care nurses were recorded with an audio recorder, and notes were taken where necessary. The intensive care nurses were also asked to convey their feelings and thoughts in writing and by e-mail to better express their feelings. After each interview (within 24 hours), the audio recordings were transcribed into a written format. During the time of the study, a total of 3 intermittent interviews were conducted with the intensive care nurses outside of their working days.

\section{Instruments}

The data in this study were collected by using a semi-structured interview form (Huang et al., 2020; Lai et al., 2020; Liu et al., 2020; Sun et al., 2020) prepared by the researchers by reviewing the literature and examining the characteristics of intensive care nurses. There was a total of 10 questions in the first part of the interview form (age, gender, educational status, marital status, having children, year of employment in the profession, year of employment in the intensive care unit, weekly working hours before the COVID-19 pandemic, weekly working hours after the COVID- 19 pandemic). In the second part, 5 open-ended questions covering general areas which did not direct the participants towards a specific response were asked to determine the experiences of the ICU nurses in their process of providing care for COVID19 patients. The open-ended questions addressed to the intensive care nurses in the study may be listed as, 'Can you talk about your experiences in caregiving for COVID-19 patients as an intensive care nurse?', 'What did you feel when you were providing care to the first COVID-19 patient? What are you feeling right now?', 'What is the meaning of providing care to COVID-19 patients for you as an intensive care nurse?', 'What are the most important difficulties/achievements that you have experienced during your period of caregiving for COVID-19 patients in your life and work?', 'How did you cope with these difficulties?' During the individual interviews, the researchers also asked different questions, which detailed the topic and were not guiding, in order to reveal the participants' views on the topic in an in-depth manner ("What else can you say about this topic?", "What do you want to express with this, could you explain a bit more?")

\section{Data Analysis}

Colaizzi's seven-step descriptive phenomenological method was used because it provides a systematic analysis of quantitative data obtained from face-to-face interviews with participants, and it has often been chosen in descriptive phenomenological studies (Morrow et al., 2015). In the first phase of the data analysis process, the audio recordings were listened to by the researchers one by one, computerized and transcribed verbatim. To make sure that the 
transcripts of the audio recordings were correct, the original audio recordings were listened to again and were compared to the initial transcriptions, and thus, the transcription process was finalized. Each of these transcripts was transferred to the MAXQDA 11 software and was again read by the researchers. In the second phase, significant and relevant statements were marked. In the third phase, the statements that had been marked were again read, and their real meanings were explored. In the fourth phase, these meanings that had been explored were categorized under certain theme clusters. In the fifth phase, the findings were combined to define phenomena comprehensively, and a detailed explanation of the findings and real-life experiences was written. In the sixth phase, the researchers reduced the detailed explanations to a short statement that -they thought- caught the aspects important to the phenomena. In the final phase, the researchers interviewed the participants again to verify whether or not the transcribed statements included the participants' real experiences, and the feedback of the participants was obtained.

Rigor and Trustworthiness: In this context, to ensure reliability in this qualitative research process, the participants were asked to read the transcripts of their interview records and confirm that their opinions were transferred correctly. This method, called participant confirmation, aims to provide internal validity and reliability. Additionally, two academics experienced in the field of qualitative research were asked to examine the data transferred to the transcripts. In this context, this reliability testing method, called peer debriefing, was also carried out (Başkale, 2016).

\section{Results}

The characteristics of participants are given in Table 1. As a result of the individual in-depth interviews with the nurses, various sub-themes were determined in line with the three main themes, which were determined as "difficulties", "achievements" and "coping strategies". The categories and themes that resulted from the interviews are presented in Table 2 .

\section{Theme 1: Difficulties}

The theme "difficulties" was examined under three subthemes. These were "Physical difficulties," "Psychological difficulties," and "Family relations and home environment."

\section{Subtheme 1.1: Physical difficulties}

In the individual in-depth interviews, the intensive care nurses stated that they had experienced general body pain, fatigue, excessive sweating, eczema and sleep problems due to heavy workload, inappropriate working hours and the quality of the equipment used since the emergence of the first case.

- I have had eczema since I wash my hands all the time due to providing care to the COVID-19 patient. I have marks of glasses and masks on my face, and they do not go away anymore because my face is irritated. I cut my hair and beard. While I provide care to a COVID-19 patient, I wear 3 layers of masks and 3 layers of clothes, and I sweat excessively. (N2)

- I can't sleep on the day when I will come to the watch duty. I work by sleeping 15 minutes a day. I am confused about the concepts of day and night now. I have back, leg, chin and neck pain. I feel extremely tired after the watch duty. I wonder if I have been infected by COVID-19 when I have difficulty in breathing. (N14)

- Fatigue and insomnia depending on the protective equipment used... I have back and neck pain due to sweating. Our noses and ears are hurt due to using masks. (N18)

\section{Subtheme 1.2: Psychological difficulties}

In the individual in-depth interviews, the intensive care nurses stated that they had experienced fear of getting infected and infecting others, stress, distress, unrest, despair, depression, fear of death and anxiety since the arrival of the first case to the unit, and these feelings had decreased over time., However, they stated that they had started to feel exhausted since the pandemic period is long.

- I go home restlessly, and it is my greatest fear to infect others at home. I also wear masks and caps all the time in my work life... It is very difficult to keep wearing masks, visors and gowns. I wear them and take them off at least 30 times a day. Each time, it takes 10 minutes, I do not want to work anymore, but there is nothing I can do. I feel exhausted. (N3)

- In the first COVID-19 case, we did not have equipment, the patient was said to probably have it. The doctors did not want to intubate him when there was cardiac arrest; it was a very bad situation for the patient. We were at serious risk. On the one hand, it was about the patient's condition, and we were facing getting infected by COVID-19. After the patient died, we learnt his result was positive, and we got quite depressed. Besides, putting my family in the patient's place and seeing there was nothing to do caused me to feel desperate. (N6) 
- $\quad$ After the first case emerged, fear, unrest and anxiety developed. These feelings decreased as we took care of the patients. When I put myself in the patients' place, I feel more fear and stress. It is frightening that people whose faces we have never seen and who are scared of us are in front of us (I believe they see us like aliens in the gown!), and another step is taken towards death. (N8)

\section{Subtheme 1.3: Family relations and home environment}

In the individual in-depth interviews, some of the intensive care nurses stated that they had separated their homes, stayed either with their colleagues in the same unit or in dormitories, had to leave their children with their elder family members and did not meet anyone socially.

- $\quad$ After my spouse and I started working in the intensive care unit for COVID-19, we had to leave our child with our parents. We can't visit them so that we do not infect them. When our child asks, "Why did you leave me?", "Why don't you hug me?" we feel very sad. (N11)

- I stay in a dormitory close to the hospital. My son will take an exam, but I cannot support his studies because I cannot visit him since things are uncertain. My daughter asks "Mom, when will you come?", and says "I miss you, I want to hug you." My spouse is tired because of taking responsibility alone and worries about me. (N14)

- I miss my family very much, but I don't show it to them so that they don't get upset. I moved into the house of a single friend of mine. I am not visiting my family because of the fear of infecting them. It was very difficult to see them from a distance and especially to tell my grandma about this situation since she is old. (N16)

Some of the intensive care nurses said they continued to live in their houses, but they did not share anything with their family members, wore masks and obeyed social distancing rules.

- I never touch or kiss my child. I observe social distancing at home, I do not sit at the table together with them, I constantly wash my hands and wear a mask. I'm not visiting my parents. (N4)

- I was away from my family for a while. Then I went home, but when my kids wanted tohug me, I had to stop myself. That was the worst of all. My daughter was 7 years old, and she kept crying, saying, 'What if you die?'. In this period, I have learned to improve first my own psychological state and then my children's psychological state! (N13)

\section{Theme 2: Achievements}

The theme "achievements" was examined under three subthemes. These were "Professionalization / Professional satisfaction," "Making sense of life: life and death," and "Team solidarity".

\section{Subtheme 2.1: Professionalization / Professional satisfaction}

In the individual in-depth interviews, the intensive care nurses stated that they had professional satisfaction during their period of caregiving for COVID-19 patients, had experience in fighting a pandemic and understood how sacred their profession was during the struggle.

- I started to work more selflessly. I believe the duty of a nurse is to provide quality care to their patients and not to leave their patients whatever happens". (N12)

- We have had very intense watch duties before. ...but we hankered for those intense watch duties while working with protective equipment and suspected cases. We have learned how sacred our profession is. (N13)

- In this period, I have felt more responsible than ever towards my patients. I can say that my professional knowledge about intervening with individuals with a pandemic disease has increased. (N16)

Subtheme 2.2: Making sense of life: life and death

In the individual in-depth interviews, the intensive care nurses stated that they started to question the meaning of life and the concept of death further as they began to provide care for COVID-19 patients.

- I have learned that we do not appreciate the value of our good days. If this pandemic comes to an end, I will spend more and more effective time with my family. I will live by enjoying and appreciating the value of every moment. (N13)

- Both our country and the world are going through a great process. Everyone should review their bad sides once again. It is so bad that little kids are introduced to masks. Wars and fights have no meaning. (N18)

- As intubated patients are put to sleep, they are not psychologically aware of anything. However, their psychological state collapses severely when they receive CPAP. They cannot perceive us with the feeling of drowning. COVID19 patients are doomed to this mask not to die, and I even have patients who say it is insufficient, the oxygen is inadequate. In this period, as I see how patients die alone, I say 'May God give everyone a 
good death'. I have realized how valuable it is even to breathe. (N6)

Table 1. Demographic characteristics of intensive care nurses

\begin{tabular}{|c|c|c|c|c|c|c|c|}
\hline Code & Age & Sex & Education & Marritus & $\begin{array}{l}\text { Year in } \\
\text { Profession }\end{array}$ & $\begin{array}{l}\text { Year in the } \\
\text { Intensive } \\
\text { Care Unit }\end{array}$ & $\begin{array}{l}\text { Weekly working } \\
\text { hours in Covid-19 } \\
\text { process }\end{array}$ \\
\hline 1 & 44 & $\mathrm{~F}$ & Undergraduate & Married & 25 & 9 & 60 \\
\hline 2 & 28 & M & Undergraduate & Married & 6 & 3 & 40 \\
\hline 3 & 27 & M & Master/P.h.D & Single & 5 & 1 & 40 \\
\hline 4 & 39 & M & Master/P.h.D & Married & 18 & 10 & 48 \\
\hline 5 & 29 & $\mathrm{~F}$ & Undergraduate & Single & 8 & 5 & 48 \\
\hline 6 & 30 & $\mathrm{~F}$ & Undergraduate & Married & 9 & 8 & 40 \\
\hline 7 & 24 & $\mathrm{~F}$ & HVHS & Single & 6 & 2 & 48 \\
\hline 8 & 25 & $\mathrm{~F}$ & Associate & Single & 8 & 1 & 48 \\
\hline 9 & 26 & M & Undergraduate & Single & 3 & 3 & 60 \\
\hline 10 & 25 & $\mathrm{~F}$ & HVHS & Single & 5 & 5 & 48 \\
\hline 11 & 27 & $\mathrm{~F}$ & Associate & Married & 9 & 6 & 48 \\
\hline 12 & 33 & $\mathrm{~F}$ & Undergraduate & Married & 11 & 6 & 48 \\
\hline 13 & 41 & M & Associate & Married & 15 & 8 & 48 \\
\hline 14 & 39 & $\mathrm{~F}$ & Undergraduate & Married & 19 & 16 & 56 \\
\hline 15 & 25 & $\mathrm{~F}$ & Undergraduate & Single & 3 & 1 & 48 \\
\hline 16 & 32 & $\mathrm{~F}$ & Master/P.h.D & Single & 13 & 3 & 48 \\
\hline 17 & 32 & M & Undergraduate & Married & 8 & 5 & 56 \\
\hline 18 & 44 & $\mathrm{~F}$ & Undergraduate & Married & 26 & 1 & 56 \\
\hline 19 & 29 & M & Undergraduate & Single & 5 & 4 & 48 \\
\hline 20 & 45 & $\mathrm{~F}$ & Undergraduate & Single & 25 & 2 & 56 \\
\hline 21 & 43 & $\mathrm{~F}$ & Undergraduate & Married & 21 & 20 & 56 \\
\hline 22 & 44 & $\mathrm{~F}$ & HVHS & Married & 25 & 8 & 56 \\
\hline 23 & 40 & $\mathrm{~F}$ & Undergraduate & Married & 19 & 1 & 60 \\
\hline 24 & 24 & M & Associate & Single & 3 & 1 & 48 \\
\hline 25 & 25 & $\mathrm{~F}$ & Undergraduate & Single & 20 & 20 & 72 \\
\hline
\end{tabular}

Note: HVHS: Health Vocational High School

Table 2. Categories and themes resulted from interviews

\begin{tabular}{lll}
\hline Category & Themes & Sub-themes \\
\hline & Difficulties & $\bullet$ Physical difficulties \\
& & $\bullet$ Psychological difficulties \\
Experiences of care-giving & Achievements & - Pamily relations and home environment \\
& & Professionalization / Professional \\
& Coping Strategies & - Taking sense of life: life and death \\
& & - Team solidarity \\
& & - Infective coping strategies \\
&
\end{tabular}




\section{Subtheme 2.3: Team solidarity}

In the individual in-depth interviews, the intensive care nurses stated that they left interpersonal conflicts aside in this period, and the healthcare personnel provided care to COVID-19 patients altogether in collaboration.

- I love my job, I continue working. As health professionals, we are at the forefront in this war. Team spirit has a big share in our psychological health. All our professionals are like the gears of a single machine that cannot be separated from each other. (N9)

- This is the determination and success of all of us, not only nurses, but also those from healthcare personnel to cleaning personnel. Health is teamwork. (N7)

- We better understood the significance of collaboration in this period. We have better demonstrated the role of nurses in human life. We must live to help others survive. This period has taught us to further cooperate with each other. (N16)

\section{Theme 3: Coping Strategies}

The theme "coping strategies" was examined under two subthemes. These were "Effective coping strategies," and "Ineffective coping strategies".

\section{Subtheme 3.1: Effective coping strategies}

In the individual in-depth interviews, the intensive care nurses stated that their spirituality increased, they prayed a lot, exercised to relax, listened to music, watched movies, read books and talked to their families on camera during this period.

- $\quad$ During this period, I started to pray. I read the Quran every evening. (N4)

- I am already someone who fulfils religious duties, and I started praying more intensively during this period. Although I worked in a gown, I fasted in Ramadan. I wasn't thankful enough before the pandemic. I watched thematic films. I read books about psychology. They were very useful. (N13)

- I talk especially to my family on camera, which relaxes me. Moreover, I try to listen to music, exercise and read books. (N14)

- I sleep a lot to relax. I also listen to music and watch movies. (N2)

\section{Subtheme 3.2: Ineffective coping strategies}

In the individual in-depth interviews, some of the intensive care nurses stated that their smoking and alcohol consumption increased during this period.

- With the onset of the pandemic, there has been an increase in my smoking and alcohol consumption to reduce my stress. (N3, N11, N15)

- I smoke and consume alcohol to relax.

\section{Discussion}

Health heroes who fight at the forefront for struggling with epidemic diseases include intensive care nurses who apply all necessary treatments to patients and take care of them and spend their working hours actively at the bedside. The world is currently facing a public health crisis which has not been observed since the Spanish flu outbreak in 1918. There are many COVID-19 cases resorting to healthcare institutions for treatment and care all around the world, and intensive care nurses usually encounter numerous difficulties in providing care to many patients with limited resources (Leblebicioğlu and Nair Aktaş, 2020).

In compliance with the studies by Chew et al. (2020), Liu et al. (2020), Mo et al. (2020), Sethi et al. (2020) and Sun et al. (2020) regarding healthcare professionals providing care to COVID-19 patients, the intensive care nurses in our study faced pain, fatigue, excessive sweating, eczema and sleep problems due to heavy workload resulting from providing care to a high number of patients, inappropriate working hours and the lacking quality or unsuitability of some protective equipment they used. Additionally, staying in protective equipment for a long time caused excessive sweating, weight loss and malnutrition, as well as weakening of their immune system. It is important for institution officials to determine maximum working hours and reasonable shifts, supply adequate and appropriate protective equipment, meet the need for trained personnel and a sufficient number of personnel for intensive care, enable healthcare personnel to eat in an adequate and balanced way and enable them to take care of themselves.

The COVID-19 pandemic is a major source of stress for healthcare professionals, as the mutated virus spreads despite the vaccine, and the number of cases does not decrease. In compliance with the literature, the intensive care nurses who were included in this study were found to experience psychological problems such as fear of infecting others and death, social isolation, burnout syndrome, stress, despair, unrest and anxiety (Cai et al., 2020; Kang et al., 2020; Lai et al., 2020; Liu et al., 2020; Ramaci et al., 2020; Romero et al., 2020; Sethi et al., 2020; Sun et al., 2020). It was discovered that the nurses experienced these problems on the highest level as they had not possessed sufficient knowledge about the pandemic since the first case, and these negative feelings decreased as the number of patients to whom they provided care increased. (N19) 
Social support is a protective factor that alleviates mental stress, eliminates psychological barriers and provides psychological resilience. Strengthening social support among nurses may mitigate the effect of their workload on health (Zhang et al., 2020). Governments should provide mental health services, including brochures, counselling and psychotherapy, by setting up mental intervention teams consisting of psychiatrists, psychologists and psychiatric nurses to reduce mental damage in intensive care nurses. To provide individual mental support for healthcare professionals, video interview programs, stress management programs, group programs aimed at communicating, talking, sharing experiences and expressing fears and hopes at the end of a working day, psychiatric tele-consultation helplines to help with the mental health problems of the hospital personnel and strategies for coping with their fear of quarantine and infection for their families and themselves (separation of living spaces, changing clothes, taking shower as soon as they reach home, wearing masks and obeying the rule of social distancing) should be established. Establishing training programs to improve their ability to struggle with a pandemic is the only effective measure to alleviate the psychological pressure on healthcare personnel. For this, training plans regarding the COVID-19 pandemic should be created, and multimedia network platforms should be used (Fagiolini et al., 2020; Izci, 2020; Liu et al., 2020; Mo et al., 2020; Sun et al., 2020).

Empowerment is a significant concept for the development of professional nursing. Empowerment of nurses is an essential condition for their participation in decision-making processes, being an effective member of the team and increasing the quality of care in the COVID-19 pandemic process (Akintujoye, 2020; Masias et al., 2020). Nurses working in intensive care units, where high-quality care is indispensable, have to be supported and empowered more than nurses working in other departments, because empowered nurses exhibit high job satisfaction and motivation, experience less work stress and less burnout and reduce negative patient outcomes. A nurse who works by taking responsibility feels stronger, which brings about professionalization (Masias et al., 2020; Sadeghi Gandomani et al., 2020). In our study, the intensive care nurses expressed that they were informed about the intervention in the pandemic, performed their jobs more meticulously and at the forefront and tried to complete the missing parts of their knowledge because they providedcare to COVID-19 patients. Thus, they became more professional and experienced more professional satisfaction, team work and altruism in this period, and they realized once again what a sacred duty intensive care nurses perform. In a study conducted in Nepal, technical personnel (nurses, laboratory and radiology technicians) and doctors were found to have high job satisfaction levels during the COVID19 period (Acharya et al., 2020). Liu et al. (2020), Sethi et al. (2020) and Sun et al. (2020) stated in their studies that lifesaving was also a responsibility of nursing, nurses were proud of their career choices, further gained their professional identities and strength in this period, could overcome every duty, experienced team spirit and continuously supported each other. Especially during the pandemic, working environments, where these sacrifices of intensive care nurses are appreciated, and rewards are given, should be created, an environment that supports motivation should be provided, and a sufficient number of nurses should be empowered for workrelated issues.

Facing the reality of death helps us see ourselves clearly, as well as understanding and enjoying life. When a person accepts the reality of death, they may live more meaningfully and to the fullest extent (Sami et al., 2020). In compliance with the studies of Sun et al. (2020), Liu et al. (2020) and Sethi et al. (2020), the intensive care nurses in our study stated that they began to further question the meanings of the concepts of life and death, valued their lives, wanted to spend more time with their families after the pandemic period, considered every healthy moment of life precious and were grateful for every healthy breath they took.

Coping with stress is necessary to reduce or eliminate the emotional tension caused by stress factors or to strengthen behaviours and emotional reactions to withstand this tension in the COVID-19 pandemic process (Ali et al., 2020). In agreement with the results of the studies of Liu et al. (2020), Sethi et al (2020) and Sun et al. (2020), the intensive care nurses in our study used more positive coping methods such as orientation towards religious practices, music, exercise, reading, watching movies and having video chats with their families. With the progress of the pandemic, the experience gained by the nurses may have enabled them to adapt to and accept the situation, increase their psychological resilience and adopt positive coping methods. Previous studies have shown that personality traits such as optimism, endurance and altruism have had 
positive effects on reducing psychological stress (Cai et al., 2020; Kaçkin et al., 2020; Sun et al., 2020). A part of the nurses in our study stated that used negative coping methods such as smoking and alcohol consumption. It was determined that these people experienced psychological trauma on a higher level. Alcohol, drug and substance use and smoking increase during mass disasters. However, this increase in alcohol and substance use and smoking brings risks with it, such as weakening of the immune system, making the body more susceptible to getting infected with the disease and developing addiction. A pandemic period, along with social isolation, social distancing, staying at home with family as it requires, may be considered as an opportunity to quit smoking and alcohol use (PAT, 2020).

It may be necessary to establish social policies and legislation for protecting the mental health of intensive care professionals and planning mental health services in the long term. Intensive care nurses who are likely to experience post-traumatic stress disorder after the pandemic may be taught to make sense of the events and progressive relaxation exercises and provided with awareness-based stress management strategies (Greenberg et al., 2020; Liu et al., 2020; Sun et al., 2020).

\section{Conclusion and Recommendations}

Our study demonstrated that all intensive care nurses who provided care for COVID-19 patients had physical and psychological problems and started to experience burnout as the pandemic period continued. It was determined that a large part of the nurses tried to overcome their negative feelings with psychological resilience characteristics and effective coping methods, whereas a small number of them had increased levels of smoking and alcohol consumption in the pandemic process. According to these results, its recommended for institutions and governments to provide sufficient equipment, to repeat training programs of intensive care nurses at certain intervals and provide these programs on social network platforms, arrange shifts in such a way that nurses can rest adequately, for nurses to follow each other with the establishment of a buddy system, to form programs that strengthen their immune system, to make arrangements for their adequate and balanced nutrition, to provide care and financial support to the families of nurses who are on duty, to provide group therapies for them to share their feelings and experiences, to present them with psychotherapy support and to establish mental health services to enable them to adopt positive coping strategies.

\section{Limitations}

This study had some limitations. There were various interruptions during the Skype conversations between the authors and the participants due to internet access issues. For this reason, some interviews had to be repeated. Therefore, the findings obtained in this study were limited only to the opinions of the 25 intensive care nurses who participated in the research process.

\section{Acknowledgments}

The authors would like to thank all the intensive care nurses.

Ethics Committee Approval: Before data collection, Ethics committee approval was gained from the Ethics Committee of Non-Interventional Clinical Studies of Burdur Mehmet Akif Ersoy University (Decision Number: GO 2020/123) and the Scientific Research Platform of Ministry of Health (Protocol number: 202005-07T11_42_35); verbal and written consent was also obtained from the intensivecare nurses, and information was given about the use of the voice recorder, and assurance was provided about the confidentiality of the voice recording. Participant numbers were used instead of the names in the research report. This research was carried out by considering the Good Clinical Practices of the Helsinki Declaration. The research was based on a 32item checklist (COREQ), which is a guideline for qualitative research. Informed consent was obtained from all individual participants included in the study.

Peer-review: External referee evaluation.

Author Contributions: Concept - S.Ş.; Design - S.Ş., A.Y.K.; Supervision - S.S.., A.Y.K; Resource - S.Ş., A.Y.K; Materials - S.S., A.Y.K.; Data Collection and/or Processing - S.Ş., A.Y.K; Analysis and/or Interpretation - S.Ş.; Literature Search - S.Ş., A.Y.K.; Writing - S.Ş.; Critical Reviews - S.S.., A.Y.K.; Other - S.S., A.Y.K.

Conflict of interest: The authors declared no potential conflicts of interest with respect to the research, authorship, and/or publication of this article.

Financial Disclosure: The authors did not receive any financial support in conducting this study.

\section{What did the study add to the literature?}

- Among health professionals, intensive care nurses are pioneers in the struggle against the COVID-19 pandemic, and their duties, roles and responsibilities have increased further.

- Struggling with a pandemic has caused intensive care nurses to be physically, psychologically and emotionally exhausted. 
- Nurses have achieved gains related to professionalization / professional satisfaction, teamwork, as well as the concepts of life and death in the care process.

- Intensive care nurses should be given coping training on crisis management, and psychological support should be provided to them.

\section{References}

Acharya S, Maharjan K, Dongol D, Ghimire A. (2020). Awareness of COVID-19 and perception of work satisfaction among healthcare workers at Patan hospital, Nepal. Journal of Patan Academy of Health Sciences, 7(1), 31-36.

Akalın B, Modanlığlu B. (2021). Evaluation of the emotional-situation and burnability levels of health professionals working in intensive care in the COVID-19 process. Acıbadem University Health Sciences Journal, 12(2), 346-352.

Akintujoye IA. (2020). Evaluating healthcare workers needs and empowering them during pandemics. Open Science Journal, 5(3), 1-7.

Ali H, Cole A, Ahmed A, Hamasha S, Panos G. (2020). Major stressors and coping strategies of frontline nursing staff during the outbreak of coronavirus disease 2020 (COVID-19) in Alabama. Journal of Multidisciplinary Healthcare, 13, 2057-2068.

Başkale H. (2016). Determination of validity, reliability and sample size in qualitative studies. Dokuz Eylul University E-Journal of Nursing Faculty, 9(1), 23-28. Buheji M, Buhaid N. (2020). Nursing human factor during COVID-19 pandemic. International Journal of Nursing Science, 10(1), 12-24.

Cai H, Tu B, Ma J, Chen L, Fu L, Jiang Y, et al. (2020). Psychological impact and coping strategies of frontline medical staff in Hunan between January and March 2020 during the outbreak of coronavirus disease 2019 (COVID 19) in Hubei, China. Medical Science Monitor, 26, 1-16.

Chegini Z, Arab-Zozani M, Rajabi MR, Kakemam E. (2021). Experiences of critical care nurses fighting against COVID-19: A qualitative phenomenological study. Nursing Forum, 1-8.

Chew NWS, Lee GKH, Tan BYQ, Jing M, Goh Y, Ngiam $\mathrm{NJH}$, et al. (2020). A multinational, multicentre study on the psychological outcomes and associated physical symptoms amongst healthcare workers during COVID-19 outbreak. Brain, Behavior, and Immunity, 88, 559-565.

Duygulu S, Başaran Açıl S, Kuruca Özdemir E, Erdat Y. (2020). COVID-19 outbreak: Nurse managers' role and responsibilities. Journal of Hacettepe University Faculty of Nursing, 7(Spe), 34-46.

Fagiolini A, Cuomo A, Frank E. (2020). COVID-19 diary from a psychiatry department in Italy. The Journal of Clinical Psychiatry, 81(3), 1-2.
Greenberg N, Docherty M, Gnanapragasam S, Wessely S. (2020). Managing mental health challenges faced by healthcare workers during COVID-19 pandemic. The BMJ, 368, 1-4.

Huang C, Wang Y, Li X, Ren L, Zhao J, Hu YI, et al. (2020). Clinical features of patients infected with 2019 novel coronavirus in Wuhan, China. The Lancet, 395(10223), 497-506.

Huang L, Lin G, Tang L, Yu L, Zhou Z. (2020). Special attention to nurses' protection during the COVID-19 epidemic. Critical Care, 24, 120.

İzci F. (2020). COVID-19 pandemy and health workers. Anatolian Journal of Psychiatry, 21(3), 335.

Kaçkin O, Ciydem E, Aci OS, Kutlu FY. (2020). Experiences and psychosocial problems of nurses caring for patients diagnosed with COVID-19 in Turkey: A qualitative study. International Journal of Social Psychiatry, 1-10.

Kang L, Li Y, Hu S, Chen M, Yang C, Yang B. (2020). The mental health of medical workers in Wuhan, China dealing with the 2019 novel coronavirus. The Lancet Psychiatry, 7(3), 14.

Kıraner E, Terzi B, Kelez Yayık A, Aydoğan S, Doğanay Ö, Yakut T, et al. (2021). The role of the intensive care nurse in the COVID-19 pandemic process. Izmir Katip Celebi University Faculty of Health Sciences Journal, 6(1), 45-48.

Lai J, Ma S, Wang Y, Cai Z, Hu J, Wei N, et al. (2020). Factors associated with mental health outcomes among health careworkers exposed to coronavirus disease 2019. JAMA Network Open, 3(3), 1-12.

Leblebicioğlu H, Nair Aktaş F. (2020). Fighting with the COVID-19 outbreak: Intensive care nursing professional and personal ethics perspective. Journal of Intensive Care Nursing, 24 (Supp-1), 73-80.

Liu Q, Luo D, Haase JE, Guo Q, Wang XQ, Liu S, et al. (2020). The experiences of health-care providers during the COVID-19 crisis in China: A qualitative study. The Lancet Global Health, 8, 790-798.

Lu H, Stratton CW, Tang YW. (2020). Outbreak of pneumonia of unknown etiology in Wuhan, China: The mystery and the miracle. Journal of Medical Virology, 92(4), 401-402.

Masias KAA, Santos JLG, Erdmann AL. (2020). Empowerment of nurses from a hospital in the south of Chile. Texto \& Contexto-Enfermagem,29(Spe), 114.

Ministry of Health (MH) (2021). Turkey COVID-19 Patient Table. Date of Access: 5 April, 2021, https://covid19bilgi.saglik.gov.tr/tr/

Mo Y, Deng L, Zhang L, Lang Q, Liao C, Wang N, et al. (2020). Work stress among Chinese nurses to support Wuhan in fighting against COVID-19 epidemic. Journal of Nursing Management, 28(5), 1002-1009. 
Morrow R, Rodriguez A, King N. (2015). Colaizzi's descriptive phenomenological method. The Psychologist, 28(8), 643-644.

Psychiatric Association of Turkey (PAT) (2020). Recommendations Regarding Alcohol and Substance Use and Use Disorder During the COVID-19 Pandemic Period. Date of Access: 22 March, 2021, https://www.psikiyatri.org.tr/TPDData/Uploads/files/ AlkolMaddeCOVID-16042020.pdf

Qiu H, Tong Z, Ma P, Hu M, Peng Z, Wu W, et al. (2020). Intensive care during the coronavirus epidemic. Intensive Care Medicine, 46(4), 576-578.

Ramaci T, Barattucci M, Ledda C, Rapisarda V. (2020). Social stigma during COVID-19 and its impact on HCWs outcomes. Sustainability, 12(9), 1-13.

Romero CS, Catalá J, Delgado C, Ferrer C, Errando C, Iftimi A, et al. (2020). COVID-19 psychological impact in 3109 healthcare workers in Spain: The PSIMCOV group. Psychological Medicine, 1-14.

Sadeghi Gandomani H, Rezaei A, Azadchehr M, Afshar M. (2020). Effectiveness of empowerment program on nurses' moral distress in intensive care units. Iranian Journal of Rehabilitation Research in Nursing, 6(3), 109-115.

Sami S, Toprak Y, Gökmen A. (2020). Changes and transformations for the meaning of life in young people in the COVID-19 process. İlahiyat Akademi, 12, 217-256.

Sethi BA, Sethi A, Ali S, Aamir HS. (2020). Impact of coronavirus disease (COVID-19) pandemic on health professionals. Pakistan Journal of Medical Sciences, 36(4), 6-11.

Sun N, Wei L, Shi S, Jiao D, Song R, Ma L, et al. (2020). A qualitative study on the psychological experience of caregivers of COVID-19 patients. American Journal of Infection Control, 48(6), 592-598.

World Health Organization (WHO) (2021). WHO Coronavirus (COVID-19) Dashboard. Date of Access: 5 April, 2021, https://covid19.who.int/

Yıldırım A, Şimşek H. (2016). Sosyal Bilimlerde Nitel Araştırma Yöntemleri. 10. Baskı, Ankara, Seçkin Yayınc1lik, ss. 101-312.

Zhang H, ZhiHong Y, Tang L, Zou P, Du C, Shao J, et al (2020). Anxiety symptoms and burnout among Chinese medical staff of intensive care unit: the moderating effect of social support. BMC Psychiatry, 20, 197. 